\title{
USA economical operator reconstruction
}

\section{Plokhotnikov Konstantin Eduardovich}

Moscow State University, Financial University under the Government of the Russian Federation, Moscow, Russia

\section{Email address:}

psygma@yandex.ru

\section{To cite this article:}

Plokhotnikov Konstantin Eduardovich. USA Economical Operator Reconstruction. International Journal of Business and Economics Research. Vol. 2, No. 5, 2013, pp. 98-111. doi: 10.11648/j.ijber.20130205.12

\begin{abstract}
In the article, the operator responsible for the U.S. economy dynamics is reconstructed on the basis of the data defining the main economic indicators of the U.S. economy. The operator is understood as an entity that manages the U.S. economy.
\end{abstract}

Keywords: Econometric Model, the Economic Operator, Data Processing, Software Package, Logarithmic Index Dynamics, the Correlation Matrix, U.S. Economic Forecast for 2013

\section{Introduction}

This work follows the author's "The model of the U.S. economy in the global context, and the forecast for 2011", which was written at the end of February 2011. This work was not published. In one of the specialized magazines author was explained that the editors are interested in the so-called "Black Swans" [1] in the economic life of the countries and the world economy as a whole, and not interested in another confirmation that the economy will exist without any significant changes.

Initially, the approach used for the simulation of the U.S. economy, has been used for the simulation of the Russian economy dynamics in the global context [2] and the forecast for 2008. Similar procedures to evaluate opportunities for the crisis appearance in 2010 development have been made for the Russian economy [3]. There also have been introduced the identifiers of the crisis, which allowed to determine the timing of crisis 2008 - 2009 on the example of the Russian economy. Namely these identifiers of the crisis were the initial elements of the mathematical model which allowed to talk about the reconstruction of the economic operator. This operator can be applied to the economy of different countries, it can also be global.

\section{U.S. Economic Indicators}

In the author's "The model of the U.S. economy in the global context and the forecast for 2011" 14 economic indicators were considered. Some of these indicators were slightly revised and re-designated. We'll give the list of these parameters, and also mention the sources of relevant statistical data [4].

To describe the econometric model of the United States economy the following set of variables was chosen:

1. I - Gross Private Domestic Investment (billions of dollars, Federal Reserve Bank of St. Louis [5]);

2. M2 - M2 Money Stock (U.S. \$, Federal Reserve Bank of St. Louis [6]);

3. ED - the ratio of the euro against the dollar (IMF Exchange Rates, Currency units per SDR [7]);

4. GDP - Real Gross Domestic Product (billions of dollars, Federal Reserve Bank of St. Louis [8]);

5. U - US Unemployment Rate (in \% [9]);

6. PI - Personal Income (billions of dollars, Bureau of Economic Analysis [10]);

7. IPI - Industrial Production Index (Index $2007=$ $100 \%$, Federal Reserve Bank of St. Louis [11]);

8. Retail — Retail sales (billions of dollars, Seasonally Adjusted, data source [12]);

9. CPI - Consumer Price Index (December $1999=$ $100 \%$, Bureau of Labor Statistics [13]);

10. Im - Imports $(2000=100 \%$, Bureau of Labor Statistics [13]);

11. Ex - Exports $(2000=100 \%$, Bureau of Labor Statistics [13]);

12. ND - USA National Debt (U.S. \$ [14]);

13. FER - Series Description, "Federal Funds Effective Rate" (Percent per year, Board of Governors of the Federal Reserve System [15]);

14. FGR - Federal Government Current Receipts (billions of dollars, Bureau of Economic Analysis [16]); 
According to baseline frequency of the primary sources of various indicators in a numbered list: days, months, and quarters. Overall, the analysis of the data was carried out based on a quarterly frequency.

As an example, Fig.1 shows two graphs: the U.S. gross domestic product, GDP (Fig.1,a) and U.S. government debt, ND (Fig.1,b). Fig.1, a shows graph of the dynamics of U.S. gross domestic product for the period from 1947/01/01 to 2012/10/01 at quarterly frequency. Fig.1,b shows a plot of the dynamics of U.S. government debt over the period from $1993 / 01 / 01$ to $2012 / 10 / 01$ at monthly frequency.

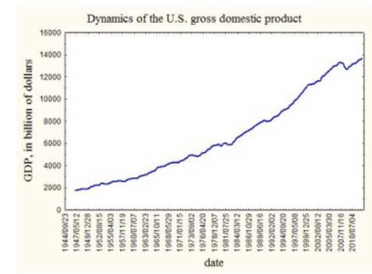

(a)

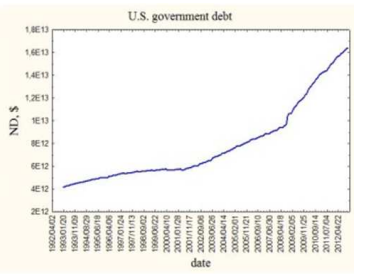

(b)
Figure 1. Dynamics of the U.S. gross domestic product from 1947/01/01 to 2012/10/01 at quarterly frequency, in billions of U.S. dollars, (a); the dynamics of the U.S. public debt from 1993/01/01 to 2012/10/01 at a monthly frequency, in U.S. dollars (b)

\section{The Logarithmic Dynamics Index}

We introduce the concept of "logarithmic dynamics index". Let our disposal there is some economic indicator $x$, the temporal dynamics of which is presented as a series of $x_{1}, \ldots, x_{N}$, then, by definition, a set of

$$
\text { Lid_ } x_{t}=\ln \left(x_{t+1} / x_{t}\right), t=1, \ldots, N-1
$$

called logarithmic dynamics index of the indicator $x$. Although the number the logarithmic dynamics index will, beginning with unity and ending at $N-1$, correlate index Lid $x_{t}$ will be with the time $t+1$.

According to the definition (1) logarithmic dynamics index belongs to the class of chain indices. Note that the logarithmic index dynamics cannot exist if one of the pairs $\left\{x_{t}, x_{t+1}\right\}, t=1, \ldots, N-1$ indicator values have different signs. In addition, logarithmic index does not exist if one or more values of the time series of vanish. All these difficulties can be overcome by an appropriate redefinition of the economic indicator. Such a transformation can be, for example, the addition of a constant to each value of the time series, considered an economic indicator. Although formally logarithmic dynamics index can be found for any of the time series, but the economic sense is logarithmic index of the volume, quantitative and qualitative indicators, which are not a chain index. It was such indicators are indicators of a numbered list previous section.

Later, in some cases, the logarithmic dynamics index will be denoted in the following abbreviated form: $L_{t}=$ Lid $x_{t}, t=$ $1, \ldots, N-1$. If we have a set of logarithmic index $\bar{L}_{t}, t=$ $1, \ldots, N-1$, then, by definition (1), you can restore the economic indicator, i.e.

$$
x_{t}=x_{1} \exp \left(\sum_{i=1}^{t-1} L_{i}\right), t=2, \ldots, N
$$

According to formula (2) if at our disposal an initial value of the index $x_{1}$ and logarithmic indexes $L_{t}, t=1, \ldots, N-1$, then the economic indicator can restore $x_{t}$ at all subsequent times $t=2, \ldots, N$. Thus, when properly prepared time series $x_{1}, \ldots, x_{N}$, we can speak of two equivalent representations of the temporal dynamics of economic indicators: the usual, as a set of $x_{1}, \ldots, x_{N}$ and using a logarithmic dynamics index, i.e. a sequence $x_{1}, L_{1}, \ldots, L_{N-1}$.

Fig. 2 shows examples of the logarithmic index of the dynamics of the gross domestic product (Fig.2,a) and U.S. government debt (Fig.2,b) with the frequency of data in a single quarter.

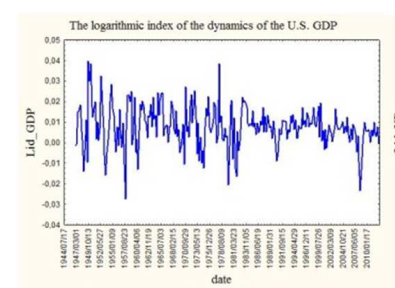

(a)

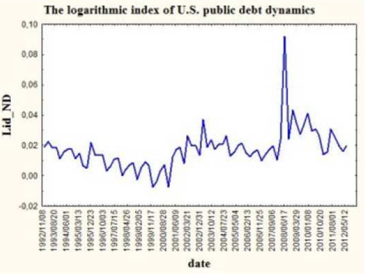

(b)
Figure 2. The logarithmic index of U.S. GDP for the period from 1947/01/01 to 2012/10/01, (a); the logarithmic index of U.S. public debt dynamics from 1993/01/01 to 2012/10/01, (b)

According to Fig.2, a logarithmic index of GDP oscillates around zero, while mostly above zero. To test the latter hypothesis in terms of statistics, we find the mean, standard deviation of the index and the number of observations. They are 0,$0078 ; 0,01 ; 263$, respectively. We choose a significance level of 0,05 , and verify the inequality: $0,0078>-\Phi^{-1}(0,05 / 2 ; 0 ; 1) \cdot \frac{0,01}{\sqrt{263}}$, where $\Phi^{-1}$ - the inverse of the normal distribution function. Inequality in bilateral criterion was checked [17], it turned out that it is true. Thus, at a significance level of 0,05 can be sure that the logarithmic index of GDP dynamics U.S. average is positive, whereby the GDP increases with time.

Similarly, for the logarithmic index of U.S. government debt in Fig.2,b find the mean, standard deviation of the index and the number of observations, which were found to be 0,$017 ; 0,013 ; 79$ respectively. Checking inequality $0,017>-\Phi^{-1}(0,05 / 2 ; 0 ; 1) \cdot \frac{0,013}{\sqrt{79}}$, we see that it is correct.

Raffle Monte Carlo logarithmic time-series dynamics of the indices of GDP and U.S. government debt. For this we construct a linear regression model appropriate logarithmic index dynamics.

Linear regression models of the dynamics of logarithmic indices as follows:

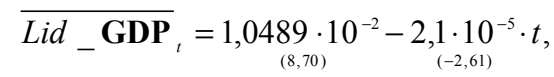

where $t=1, \ldots, 263$;

$$
\overline{\text { Lid_NDD }}_{t}=\underset{(2,60)}{6,998 \cdot 10^{-3}}+\underset{(4,35)}{2,54 \cdot 10^{-4} \cdot t,}
$$


where $t=1, \ldots, 79$.

In (3), (4) in brackets exhibited values of Student that because they are more noticeably modulo 2 indicate that all the coefficients of regression models significant at 0,05 level of significance. In (3), (4) the numbering of times corresponds to quarterly frequency ranges of 1947/01/01 2012/10/01 for GDP and 1993/01/01 — 2012/10/01 for U.S. government debt, respectively. Fig. 3 shows scatter plots and graphs of linear regression models (3), (4) of GDP and U.S. government debt. From the graphs in Fig. 3 shows that the overall rate of GDP growth is slowing, and the growth rate of public debt increases.

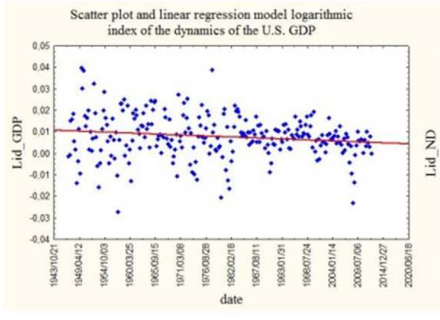

(a)

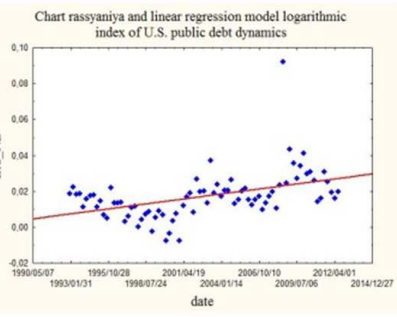

(b)
Figure 3. Scatter plot and regression model (3) of the logarithmic index of the dynamics of the U.S. GDP, (a); scatter plot and regression model (4) of the logarithmic index of the dynamics of U.S. debt, (b)

Taking into account (3), (4), raffle the Monte Carlo dynamics of logarithmic indices by the formulas:

$$
\begin{aligned}
& \mathrm{Lid}_{-} \mathbf{G D P}_{t}={\overline{\mathrm{Lid}} \mathbf{} \mathbf{G D P}_{t}}_{t}+10^{-2} \cdot \xi_{t}, \quad t=1, \ldots, 263 ; \\
& \text { Lid_ND } \mathbf{N D}_{t}=\overline{\operatorname{Lid} \_\mathbf{N D}}_{t}+1,3 \cdot 10^{-2} \cdot \boldsymbol{\xi}_{t}, t=1, \ldots, 79 ;
\end{aligned}
$$

where $\xi \sim N(0,1)$ - normally distributed random variable, and the values $10^{-2}$ and $1,3 \cdot 10^{-2}$ represent standard deviations of the corresponding series of logarithmic dynamics index.

Raffle random variables $\xi$ in $\left(3^{\prime}\right),\left(4^{\prime}\right)$ and build the corresponding logarithmic dynamics index. Using equation (2), we find the time series model parameters and compare them with the actual time series. Fig. 4 shows a comparison of model (dashed line) and true (solid line) time series of GDP (Fig.4,a) and U.S. government debt (Fig.4,b).

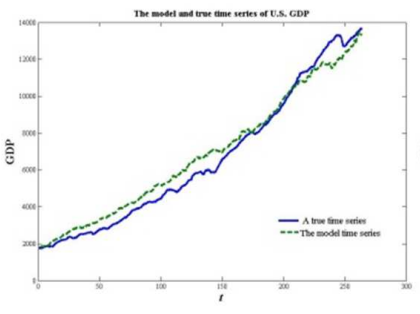

(a)

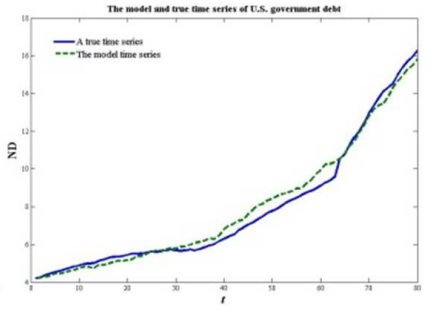

(b)
Figure 4. The model and true time series of U.S. GDP, (a); the model and the true time series of U.S. government debt, (b)

Analysis of Fig. 4 shows that, based on the logarithmic index of the dynamics of playing with the Monte-Carlo, it is possible to achieve good agreement of model and real time series. Note that the compliance will remain even if the index models take just a regression model, i.e.

$$
\begin{aligned}
& L i d_{-} \mathbf{G D P}_{t}={\overline{\operatorname{Lid}{ }_{-} \mathbf{G D P}}}_{t}, t=1, \ldots, 263 ; \\
& L i d_{-} \mathbf{N D}_{t}=\overline{L i d \_\mathbf{N D}}_{t}, t=1, \ldots, 79 .
\end{aligned}
$$

Fig. 5 shows a comparison of model time series built with $\left(3^{\prime \prime}\right),\left(4^{\prime \prime}\right)$, with the corresponding true time series. When building a logarithmic index without stochastics, i.e. according to $\left(3^{\prime \prime}\right),\left(4^{\prime \prime}\right)$, the time series model are a form of regression curves.

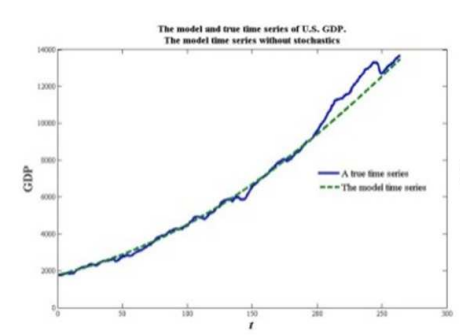

(a)

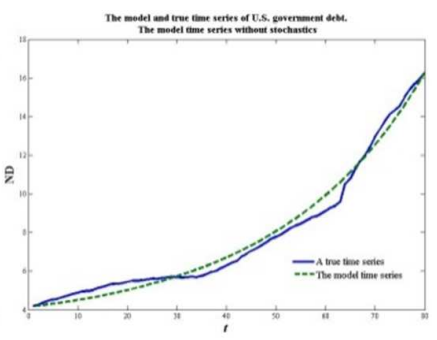

(b)
Figure 5. A comparison of the true and the model time series of U.S. GDP, the model time series without stochastics, (a); a comparison of the true and the model time series of U.S. government debt, the model time series without stochastics, (b)

Compare the regular index $I$ with a logarithmic index dynamics $L$. We write the definition of both indices in a comparable form:

$$
I_{t}=\frac{x_{i+1}}{x_{t}}-1, L_{t}=\ln \frac{x_{t+1}}{x_{i}}, t=1, \ldots, N-1 .
$$

Indices of the dynamics in (5) correspond to those of the form: $I(\xi)=\xi-1, L(\xi)=\ln \xi$, the appearance of which is shown in Fig.6.

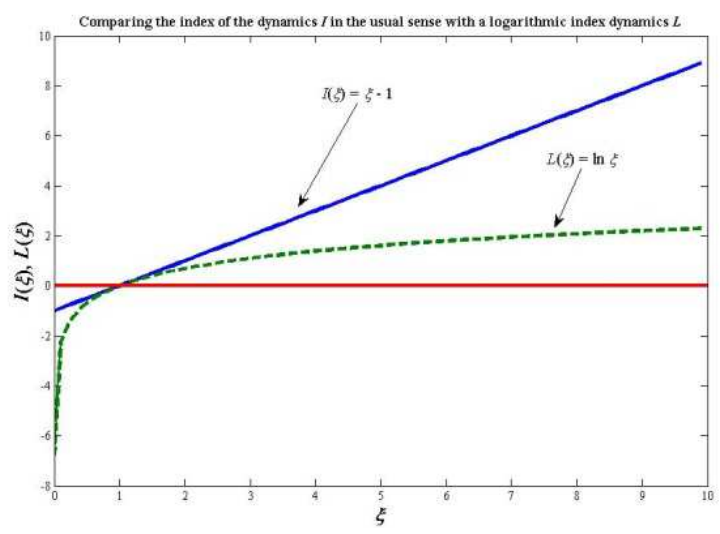

Figure 6. A comparison of the dynamics of the index I in the usual sense with logarithmic dynamics index $L$

According to Fig.6, both indices are close to each other and to zero in the vicinity $\xi=1$, i.e. in the neutral point, which characterizes the absence of changes in the rate. When $\xi>1$, i.e. at the growth of index, the usual index is always more common logarithmic. At $0<\xi<1$, i.e. at decreases indicator usual index changes in the range $(-1 ; 0)$, 
while logarithmic index in a semi-infinite range $(-\infty ; 0)$. Thus, unlike usual index logarithmic dynamics index varies across the range $(-\infty ;+\infty)$ and at $\xi>0$ is always less than the usual index.

Note that larger values of the logarithmic index, i.e. values of $|L|>1$, a rarity for a typical set of economic indicators. This fact is extremely important, because it is logarithmic dynamics index can make a variety of economic indicators comparable. This compatibility will be understood from the perspective of economic management by an operator. It is through the operator can talk about the comparability of economic indicators presented in the form of a logarithmic dynamics index.

Fig. 7 shows the image of a prospective operator who presses the gas and brake pedals under the name: the dynamics of gross investment, I; monetary aggregate M2; ratio of the euro against the dollar, ED; ...; operating earnings in the U.S. budget, FGR.

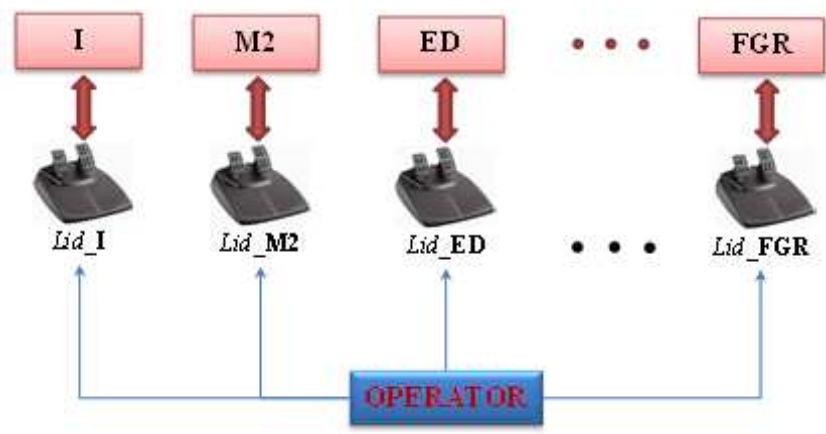

Figure 7. Image of how economic indicators are positioned, corresponding logarithmic dynamics index and prospective operator

Scenario management of the economy following the alleged operator. When logarithmic measure of dynamics is positive, it means that the operator presses the "gas pedal" of the indicator. Conversely, when the logarithmic measure of dynamics is negative, it means that the operator presses the "brake pedal" the indicator. Fig.7 presents the images of the two pedals - accelerator and brake for each economic indicator.

\section{Statistical Characteristics of Logarithmic Index}

We consider a number of statistical characteristics of all 14 logarithmic dynamics index. We restrict ourselves of a time range from 2000/01/01 to 2012/07/01 at a frequency of one quarter. Range selection due to the fact that it all 14 indexes available (except at Lid FGR 2012/07/01). In the raw data value of the index at the time of $2012 / 10 / 01$ FGR missing. That is why at the time 2012/07/01 the index Lid_FGR also absent. This index has been supplemented with the model forecast $\operatorname{ARIMA}(2,1,0)$ with a statistically significant (at the 0,05 level) coefficients. Fig. 8 shows a fragment of the table with the values of the logarithmic index of all 14 economic indicators.
We study the statistical properties of the logarithmic dynamics index: the average value (Mean), standard deviation (S.D.), the minimum standard deviation (Min S.D.), the maximum standard deviation (Max S.D.), minimum (Min), maximum (Max), minimum among the 14 indicators (Mega Min), the maximum of the 14 indicators (Mega Max).

On the basis of bilateral statistical test to evaluate on the level of 0,05 , significantly if the average value of the index is different from zero (the significance of the mean). The value of " 0 " denote the fact that the average non-significant different from zero, the value of " 1 " denote the fact that the average value is significantly different from zero.

\begin{tabular}{|c|c|c|c|c|c|c|c|c|c|c|c|c|c|c|}
\hline & 1 & ${ }_{\text {Lid_M2 }}^{2}$ & $\mathrm{LiddED}^{3}$ & Lid_GDP & $\begin{array}{c}5 \\
5 \\
\text { LiduU }\end{array}$ & $\begin{array}{l}6 \\
\text { Lid_PI }\end{array}$ & $\begin{array}{l}77|| P \mid \\
\text { Lid_I }\end{array}$ & ${ }_{\text {id_Retail }}^{8}$ & Lid_CPI & $\begin{array}{l}10 \\
\text { Lidilm }\end{array}$ & Lid_Ex & $\begin{array}{l}12 \\
\text { LidNND }\end{array}$ & $\begin{array}{l}13 \\
\text { Lid_EER }\end{array}$ & $\begin{array}{c}14 \\
\text { Lid_FGR }\end{array}$ \\
\hline & & & & & & & & & & & 0.009 & & & \\
\hline & 0,032 & 0,003 & 0.011 & 0,010 & - -0.0255 & 0,002 & 0,014 & 0,008 & 0,004 & 0,008 & 0.012 & 0,026 & 0,236 & 0,077 \\
\hline 年 & -0.007 & 0.011 & $\begin{array}{c}-0.040 \\
-0.032\end{array}$ & $\begin{array}{l}0.004 \\
0.008\end{array}$ & $\begin{array}{l}-0.038 \\
-0.026\end{array}$ & 0.014 & $\begin{array}{r}0.005 \\
0.004\end{array}$ & $\begin{array}{l}0.020 \\
0.018\end{array}$ & $\begin{array}{l}0.012 \\
0.011\end{array}$ & $\begin{array}{l}0.025 \\
0.0233\end{array}$ & $\begin{array}{l}0.008 \\
0.022\end{array}$ & $\begin{array}{l}0.013 \\
0.015\end{array}$ & $\begin{array}{l}0.175 \\
0.1626\end{array}$ & $\begin{array}{l}0.012 \\
0.021\end{array}$ \\
\hline 5//7/:01 & $\begin{array}{l}0,024 \\
0,049\end{array}$ & , 0,015 & $\begin{array}{l}-0,022 \\
-0,026\end{array}$ & $\begin{array}{l}0,0008 \\
0,005\end{array}$ & $\begin{array}{l}0.066 \\
0,000\end{array}$ & 0,015 & $\begin{array}{l}-0,0,044 \\
0,008\end{array}$ & 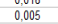 & 0,004 & 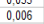 & $\begin{array}{l}0.028 \\
0.008\end{array}$ & 0 & $\begin{array}{l}0,162 \\
0,140\end{array}$ & $\begin{array}{l}0,02121 \\
0,026\end{array}$ \\
\hline $2005 / 100 / 01$ & 0,026 & 0,012 & 0.012 & 0,013 & $-0,048$ & 0,026 & 0,010 & 0,027 & 0,005 & 0,000 & 0,007 & 0,022 & 0,113 & 0,044 \\
\hline 101010 & 0,007 & $0,0,14$ & 0.045 & 0,004 & - -0.021 & 0,016 & 0,006 & 0,003 & 0,016 & 0.030 & 0.016 & 0,015 & $\begin{array}{l}0,096 \\
0\end{array}$ & 0,011 \\
\hline & & & & & & & & & & & & & & $\begin{array}{l}0,018 \\
0,011\end{array}$ \\
\hline 10:0101 & $\begin{array}{l}-0.004 \\
-0.004\end{array}$ & 0 & 0.017 & $\begin{array}{l}0.001 \\
0.001\end{array}$ & 0.015 & 0.018 & 0.010 & 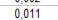 & 0.009 & 0.004 & 0.017 & 0.017 & $\begin{array}{l}0,000 \\
0,002\end{array}$ & $\begin{array}{l}0.0117 \\
0.026\end{array}$ \\
\hline & 0,023 & 0,019 & 0.028 & 0,009 & 0,000 & 11 & 0,011 & 0,008 & 0,018 & 0,035 & 0,015 & 0,010 & $-0,001$ & $\begin{array}{l}0.0200 \\
0,006\end{array}$ \\
\hline & $-0,007$ & 0,009 & 0.019 & 0,00 & 0,036 & 0,010 & 0,002 & 0,008 & & & 0,007 & & $\begin{array}{l}-0,034 \\
\end{array}$ & $-0,003$ \\
\hline & & 0,016 & & 0,004 & 0,028 & 0,016 & 0,0019 & 0,013 & & & 0.018 & 0,017 & $\begin{array}{l}-0,121 \\
-0.318\end{array}$ & 0,005 \\
\hline & $\begin{array}{l}-0.034 \\
-0.009\end{array}$ & 0,022 & $\begin{array}{l}0.0434 \\
0.042\end{array}$ & $=0,0,04$ & 065 & 0,0212 & $\begin{array}{l}-0,033 \\
-0.015\end{array}$ & $\begin{array}{l}-0,008 \\
0,006\end{array}$ & & 36 & 0,024 & $\begin{array}{l}0.040 \\
0.010\end{array}$ & $\begin{array}{l}-0,348 \\
-0.420\end{array}$ & $-0,010$ \\
\hline & $\begin{array}{l}-0.037 \\
-0.037\end{array}$ & 0.004 & -0.038 & $\begin{array}{l}-0.0009 \\
-0.009\end{array}$ & 0.1818 & 005 & $\begin{array}{l}-0.033 \\
-0.033\end{array}$ & -0.0 & 0.012 & 010 & 0.098 & 0.024 & -0.073 & $=0,0$ \\
\hline 07701 & & 0,038 & $-0,132$ & & 0,135 & -0.014 & -0.043 & -0,090 & -0.027 & -0,162 & & 092 & -1343 & $\begin{array}{l}-0.0718 \\
-0,018\end{array}$ \\
\hline & $\begin{array}{l}-0.150 \\
-0.0\end{array}$ & . & 0 & $-0,013$ & 0,186 & 34 & 0,0003 & 0.024 & 107 & $-0,070$ & -0,023 & 0,024 & $-1,017$ & $-0,102$ \\
\hline & & & & & 14 & & & 0,002 & & & 然6 & & & $-0,005$ \\
\hline & 0.082 & 0.11 & 0.033 & 0,01 & 0031 & & 14 & . & & & & 27 & & $\begin{array}{l}-, 0,000 \\
0,020\end{array}$ \\
\hline & 0.043 & 0,003 & -0.067 & 0,006 & $\begin{array}{l}-0.017 \\
-0.74\end{array}$ & 19 & 19 & 0.015 & 03 & 0.019 & 0.016 & 0.034 & 0.05 & $\begin{array}{l}0,050 \\
0,023\end{array}$ \\
\hline & 0.038 & 0.00 & -0.084 & 0.00 & 14 & 16 & & 0.014 & & & & & & 0.017 \\
\hline 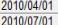 & $\begin{array}{l}0,039 \\
-0,013\end{array}$ & 0,0 & $\begin{array}{l}0.0 \\
0.0\end{array}$ & 00 & 10 & 09 & 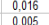 & 0,007 & , & $\begin{array}{l}-0,008 \\
-0,023\end{array}$ & $\begin{array}{l}0.022 \\
0.027\end{array}$ & 0.030 & $\begin{array}{l}-0.035 \\
0.000\end{array}$ & $\begin{array}{l}0,026 \\
0.014\end{array}$ \\
\hline 11010101 & 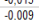 & 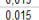 & . 0.076 & 0,0 & sis & 27 & & 年 & $\begin{array}{l}0,01 \\
0.12\end{array}$ & 00 & 0.036 & 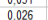 & $\begin{array}{l}0.005 \\
0.075\end{array}$ & $\begin{array}{l}0,014 \\
0.019\end{array}$ \\
\hline 2011010101 & 0,035 & 0,016 & 0.051 & 0,006 & 0,004 & 0,006 & 0,003 & 0,015 & 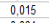 & 0,049 & 0,023 & & 0,518 & 0,005 \\
\hline & 0,019 & & $-0,019$ & 0,00 & 04 & & & 0,011 & 0,004 & & 0,0 & & -0.113 & -0.005 \\
\hline & 0.071 & 0.024 & -0.046 & 0.011 & 41 & 03 & 12 & 0.019 & 101 & 001 & 016 & & 0.128 & 0.009 \\
\hline & & 0,0 & - 0,0282 & 0,000 & 11 & & & & & & & & & 0,050 \\
\hline & , 0000 & , & 作 & & 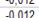 & 05 & & & & & & & 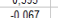 & \\
\hline & 0.002 & 0.02 & 0.036 & -000 & & & & & & 000 & 1004 & 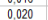 & .0.010 & 0.024 \\
\hline
\end{tabular}

Figure 8. A fragment of the logarithmic values of the dynamics index of 14 indicators

Table 1 lists the required number statistics. We note the following features of the data Table 1.

Table 1. General statistics of logarithmic index

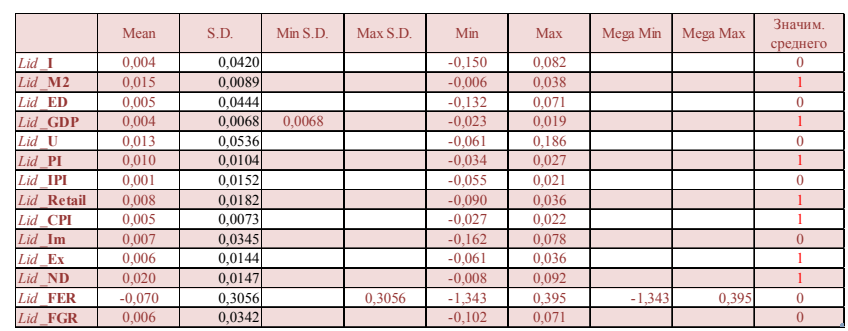

1. The mean values of all indexes except Lid_FER, positive. This can be interpreted to mean that the economic operator in the United States prefers the state average growth in most indicators.

2. Maximum and minimum volatility (S.D.) have indices Lid_FER and Lid_GDP respectively. This could be interpreted in the sense that most sharply operator regulates the growth and slowing down of profitability of the federal funds. The least variably control the real gross domestic product of the United States. Given that the average Lid_GDP significantly positive, one can conclude that the average U.S. GDP increases and this increase is statistically significant at the 0,05 level.

3. Only one negative average logarithmic index of 
effective rates federal funds, Lid_FER means that the rate was negative. In such cases it has to be taken into account that the resulting mean value will be at the 0,05 level insignificantly differing from zero. And, more curious mega extremes of logarithmic indexes associated with the index Lid_FER, which in the period from $2000 / 01 / 01$ to $2012 / 04 / 01$ most heavily exposed inhibition (peaking at the date 2008/07/01 (2008/10/01)) and growth (peaking at 2012/01/01 (2012/04/01)). The peak inhibition of yield on federal funds corresponds exactly to the deployment of the global financial crisis in the fourth quarter of 2008 peak acceleration of profitability in subsequent instants of time can be attributed to the monetary anti-crisis policy of the U.S. Federal Reserve.

4. According to the last column of the Table 1, at 0,05 statistically significant was the growth of the seven indexes: Lid_M2, Lid_GDP, Lid_PI, Lid_Retail, Lid_CPI, Lid_Ex, Lid_ND. The other indices are also regulated, but their average deviation from zero is insignificant.

We can now give the first reconstruction of the U.S. economic operator without temporal characteristics, i.e. operator "integrated over", averaged over the length of time from $2000 / 01 / 01$ to $2012 / 10 / 01$.

The average operator presses the gas pedal seven indicators from fourteen. Given the average values of the indices in the Table 1, will focus in the Table 2 intensity gas pedal is pressed by the operator. The indices in the Table 2 are distributed in descending order of the rate of growth: the national debt (ND), monetary aggregate M2 (M2), U.S. personal income $(\mathrm{PI})$, exports $(\mathrm{Ex})$, the consumer price index (CPI) and real gross domestic product (GDP).

Table 2. Descending order of intensity of growth of seven indices with a statistically significant mean values

\begin{tabular}{lllllll}
\hline Lid_ND & Lid_M2 & Lid_PI & Lid_Retail $_{-}$ & Lid_Ex $_{-}$ & Lid_CPI $_{-}$ & Lid_GDP $_{-}$ \\
\hline 0,020 & 0,015 & 0,010 & 0,008 & 0,006 & 0,005 & 0,004 \\
\hline
\end{tabular}

Fig. 9 shows the geometrical illustration of the intensity ratio with which the economic operator presses the pedal to the growth of each economic indicator Table 2. The ratio between the growth rate of the fastest indicator of public debt (ND) and the speed of the slowest growth rate of U.S. GDP (GDP) is in the ratio of 5:1. Fig. 9 sizes of squares and arrows marked downward trend in the intensity of growth index sequence in accordance with the Table 2.

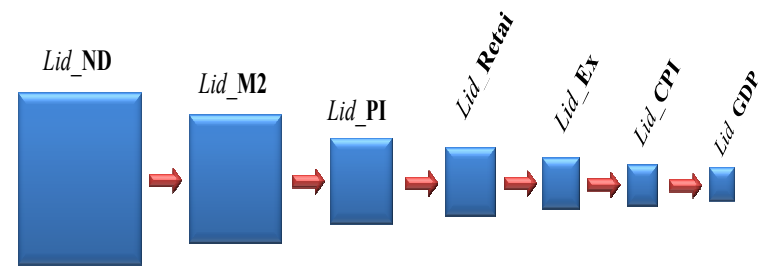

Figure 9. Illustration ratio of growth rates of 7 logarithmic indexes

\section{A Measure of the Operator's Management the System of Indicators}

We define a measure $\kappa$ of the control action by the operator some economic indicator $x$, presented in the form of a time series $x_{1}, \ldots, x_{N}$. We define the logarithmic dynamics index Lid $x_{t}, t=1, \ldots, N-1$ and the value of the form:

$$
\eta_{t}=\frac{\mid L i d_{-} x_{t}-\operatorname{mean}\left(L i d_{-} x\right) \sqrt{N-1}}{-\Phi^{-1}(\alpha / 2,0,1) \times \text {... }\left(\operatorname{Lid}_{-} x\right)},
$$

$t=1, \ldots, N-1, \Phi(u, 0,1)$ - normal distribution function with mean 0 and standard deviation $1, \alpha$ - level of significance, mean and S.D. - mean and standard deviation of the number of Lid_ $x_{t}, t=1, \ldots, N-1$.

If the $\eta_{t} \leq 1$, it means that at the level $\alpha$ value Lid $x_{t}$ insignificantly differs from the average index logarithmic mean (Lid $x$ ). If the $\eta_{>}>1$, it means that at $\alpha$ value Lid $x_{t}$ differs significantly from the average index logarithmic mean $\left(\right.$ Lid_ $x$ ). With the condition $\eta_{l}>1$ we can talk about the significant management operator of the economic indicator. We introduce a measure of control by the operator of the economic indicator as follows:

$$
\kappa_{t}=\eta_{t} \theta\left(\eta_{t}-1\right),
$$

where $t=1, \ldots, N-1, \theta-$ unit function, i.e. $\theta(u)=1, u>0$ and $\theta(u)=0, u<0$. Fig. 10 shows a graph of the function (7), i.e. function $\kappa(\xi)=\xi \theta(\xi-1)$.

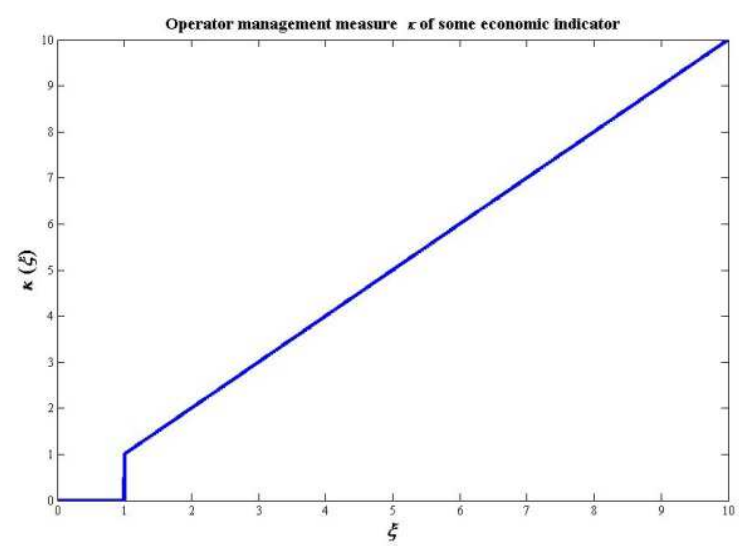

Figure 10. Operator management measure $\kappa$ of some economic indicator

According to (6), (7), a measure of control by the operator single indicator depends on the level of significance $\alpha$. Thus, we reconstructed the operator of the U.S. economy will be expressed, identified in connection with the chosen level of significance $\alpha$.

Since the operator manages several indicators, so far it makes sense to define a measure of the control system of economic indicators. Let defined management measure $\boldsymbol{\kappa}^{(m)}$, $m=1, \ldots, M$ each of indicators. We define two measures of performance management systems. Let's call them "additive measure of economic management", $M c \_a$, and the "multiplicative measure of economic management", $M c_{-} m$. We define them by the formulas: 


$$
\begin{aligned}
& M c_{-} a_{t}=\frac{1}{M} \sum_{m=1}^{M} \kappa_{t}^{(m)}, \\
& M c_{-} m_{t}=\sqrt[M]{\prod_{m=1}^{M} \kappa_{t}^{(m)}},
\end{aligned}
$$

where $t=1, \ldots, N-1$.

Management activities (8), (9) is nothing but the arithmetic and geometric means, respectively, they differ in the following. If at least one of the measures in the set $\kappa^{(m)}$, $m=1, \ldots, M$ is equal to zero, in contrast to the additive measure $M c \_a$, multiplicative measure $M c \_m$ vanishes. Management activities (8), (9) are the same as the individual performance management measures are the same, i.e.

$$
M c \_a=M c \_m=\kappa_{0}, \kappa^{(1)}=\ldots=\kappa^{(M)}=\kappa_{0} .
$$

Parameter $\kappa_{0}$ in (10) is greater than or equal to unity, i.e. $\kappa_{0} \geq 1$, because to determine (7) the minimum statistically significant effect on the magnitude of power unit.

In general, the additive and multiplicative management measures may be different, i.e. condition (10) is not satisfied.

Construct on the 0,05 level of significance dependence of the additive $M c \_a$ and multiplicative $M c \_m$ management measures on time in relation to the 14 economic indicators of the U.S. economy. We index quarterly times 2000/01/01, $2000 / 04 / 01, \ldots, 2012 / 07 / 01$ index $t$, which takes the values $1, \ldots, 51$. Fig. 11 shows the graphs of the two management measures, depending on the time $t, t=1, \ldots, 51$.

According to Fig.11 additive measure control over the multiplicative measures in each of the points of observation. A nonzero multiplicative measures means that the operator controls all statistically significant 14 performances. This is the case for the two points in time. Table 3 shows the number of times the data values and the values of the additive and multiplicative operator control measures the U.S. economy.

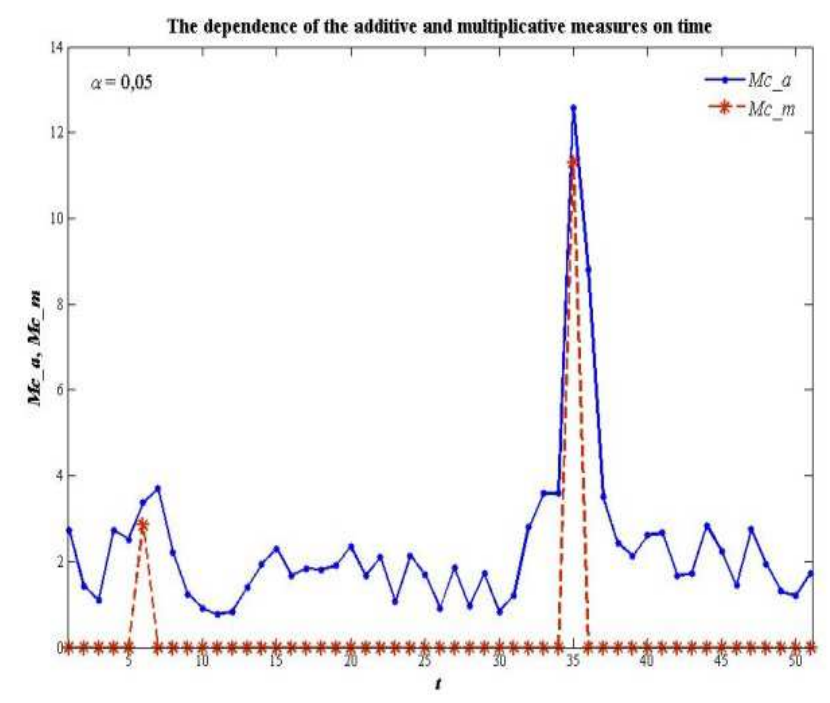

Figure 11. The dependence of the additive $M c \_a_{t}$ and multiplicative $M c \_m_{t}$ management measures on time, $t$
Table 3. Two specific points in time and the numerical values of the additive and multiplicative management measures U.S. economy

\begin{tabular}{lll}
\hline Time & $\begin{array}{l}\boldsymbol{t}=\mathbf{6} ; \\
\mathbf{2 0 0 1 / 0 4 / 0 1}(\mathbf{2 0 0 1 / 0 7 / 0 1 )}\end{array}$ & $\begin{array}{l}\boldsymbol{t}=\mathbf{3 5} \\
\mathbf{2 0 0 8 / 0 7 / 0 1}(\mathbf{2 0 0 8 / 1 0 / 0 1 )}\end{array}$ \\
\hline Mc_a & 3,373 & 12,568 \\
Mc_m & 2,857 & 11,299 \\
\hline
\end{tabular}

In the Table 3, together with the global financial crisis that erupted in the fourth quarter of $2008(2008 / 10 / 01)$, there is a time 2001/07/01, when the economic operator pressed the pedal all 14 at once. In this case, the global financial crisis on the average regulated economic operator is four times more intense than at other times.

Thus, at a significance level of 0,05 the U.S. economic operator is fully manifested, i.e. actively managed simultaneously by all 14 performances at times 2001/07/01, $2008 / 10 / 01$. In other times, he managed the smaller number of indicators, with no points in time from the interval 2000/04/01 - 2012/10/01, when the economic operator, would not run any of the indicators.

We define the additive and multiplicative management measures at a significance level of 0,01. Fig. 12 shows the response of the two plots of the additive and multiplicative management measures on time. The graph multiplicative measures, $M c \_m$ shows that there is only one peak in comparison with the two on the same graph Fig.11. This peak refers to the date 2008/07/01 (2008/10/01), which corresponds to the date of the beginning of the global financial crisis. Note that the control measures at 2008/07/01 $(2008 / 10 / 01)$ were $M c \_a=9,563 ; M c \_m=8,598$, which is slightly smaller number of indicators Table 3 .

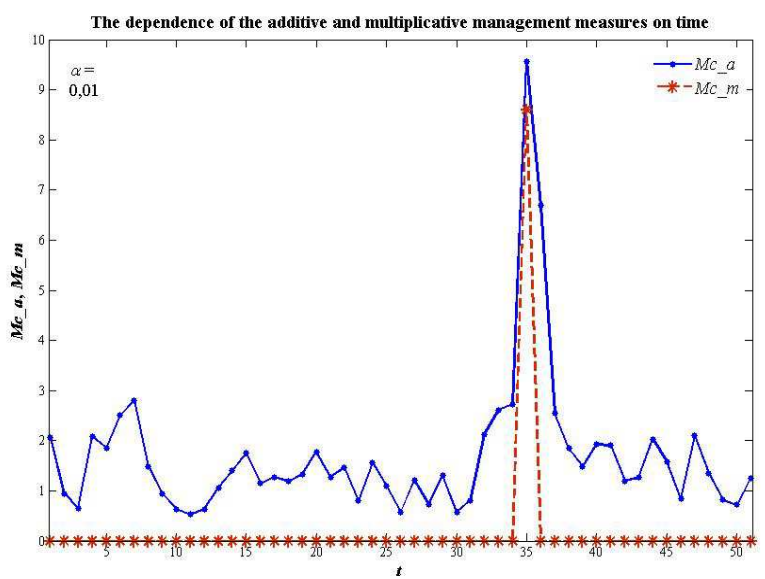

Figure 12. The dependence of the additive $M c \_a_{t}$ and multiplicative $M c \_m_{t}$ management measures on time, $t$

Thus, at the 0,01 level of significance takes place only one time 2008/07/01 (2008/10/01), when the U.S. economic operator appeared in full, i.e. he actively worked on all 14 economic indicators at the same time.

Summarizing the results for the two levels of significance (Fig.11,12), we can assume that the existence of special points in time 2008/07/01 (2008/10/01) in the management 
of the operator of the U.S. economy. At this point, the operator of the U.S. economy has sharply increased control action, which on average has increased by three times every economic indicator. To assess the impact of the sign by the operator on the $m$-th variable to check a couple of inequalities:

$$
\begin{aligned}
& \text { Lid _ } x_{t o}^{(m)}>\operatorname{mean}\left(\operatorname{Lid}_{-} x^{(m)}\right)- \\
& \Phi^{-1}(\alpha / 2,0,1) \times \frac{\text { S.D. }\left(\text { Lid } d x^{(m)}\right)}{\sqrt{51}}>0, \\
& \text { Lid } x_{t^{\circ}}^{(m)}<\operatorname{mean}\left(\text { Lid }_{-} x^{(m)}\right)+ \\
& \Phi^{-1}(\alpha / 2,0,1) \times \frac{\text { S.D. }\left(\text { Lid }_{2} x^{(m)}\right)}{\sqrt{51}}<0,
\end{aligned}
$$

where $m=1, \ldots, 14 ; t_{*}=35(2008 / 07 / 01 \quad(2008 / 10 / 01))$; 51 - length of the time series of economic indicators, minus $1 ; \alpha$ - significance level.

If the correct pair of inequalities (11), the rate of change of the $m$-th variable is significant positive (at the level of $\alpha$ ), if the correct pair of inequalities (11'), then the rate of change of $m$-th variable is significantly negative. Signs manipulated by the operator for each of the 14 variables are on Table 4 on the level of significance $\alpha=0,05$, calculated in accordance with verification of the inequalities (11), (11'). The result is not changed and the level of significance $\alpha=0,01$.

Analysis of the results tabulated in Table 4, said that during the financial crisis that began at the time 2008/07/01 (2008/10/01), 11 of the 14 variables were declining, while the monetary aggregate $\mathrm{M} 2$, the ratio of unemployed to the economically active population, U, U.S. government debt, $\mathrm{ND}$, on the contrary, increased.

Table 4. Signs of control action of the operator for each 14-variables at the time of the financial crisis 2008/07/01 (2008/10/01)

\begin{tabular}{lllllll}
\hline$L_{-} \mathbf{I}$ & $L_{-} \mathbf{M 2}$ & $L_{-}$ED & $L_{-} \mathbf{G D P}$ & $L_{-} \mathbf{U}$ & $L_{-} \mathbf{P I}$ & $L_{-} \mathbf{I P I}$ \\
\hline- & + & - & - & + & - & - \\
& & & & & & \\
$L_{-}$Retail & $L_{-} \mathbf{C P I}$ & $L_{-} \mathbf{I m}$ & $L_{-} \mathbf{E x}$ & $L_{-} \mathbf{N D}$ & $L_{-} \mathbf{F E R}$ & $L_{-}$FGR \\
& - & - & - & + & - & - \\
\hline
\end{tabular}

In short we can give the following formula of the financial crisis: the majority of economic indicators are falling, except such as the monetary aggregate M2, public debt and the number of unemployed.

Estimate the probability of economic operator in each of the available time instants, $t, t=1, \ldots, 51$. To do this we assume that each of the logarithmic indexes $L_{t}^{(m)}, t=1, \ldots, 51$; $m=1, \ldots, 14$ can be approximately described by the normal law with an average mean $\left(L^{(m)}\right)$ and standard deviation S.D. $\left(L^{(m)}\right)$. We define the probability of a deviation of the logarithmic index from the average mean $\left(L^{(m)}\right)$ by the formula:

$$
p_{t}^{(m)}=\left\{\begin{array}{c}
2 \Phi\left(L_{t}^{(m)}, \operatorname{mean}\left(L^{(m)}\right), \text { S.D. }\left(L^{(m)}\right)\right), \\
L_{t}^{(m)}<\operatorname{mean}\left(L^{(m)}\right) ; \\
2\left(1-\Phi\left(L_{t}^{(m)}, \operatorname{mean}\left(L^{(m)}\right), \text { S.D. }\left(L^{(m)}\right)\right)\right), \\
L_{t}^{(m)} \geq \operatorname{mean}\left(L^{(m)}\right) ;
\end{array}\right.
$$

where $\Phi$ - normal distribution function with a mean value mean $\left(L^{(m)}\right)$ and standard deviation S.D. $\left(L^{(m)}\right) ; t=1, \ldots, 51 ; m$ $=1, \ldots, 14$.

Probability (12) is normalized so that it is equal to one when the logarithmic index coincides with the average value. As the distance from the average decreases, probability approaches zero. Considering the likelihood of logarithmic indexes $p_{t}^{(1)}, \ldots, p_{t}^{(14)}$ independent, we find the probability at time $t$ of the whole system performance $P_{t}$, i.e.

$$
P_{t}=\prod_{m=1}^{14} p_{t}^{(m)}
$$

where $t=1, \ldots, 51$.

Fig. 13 shows the dynamics of the joint probability of the logarithmic indices deviations from the mean values on the time $t, t=1, \ldots, 51$, calculated according to the formulas (12) and (13). We note a sharp peak in the behavior of the probability that accounts for time corresponding to the beginning of the global crisis $t=35$ (2008/07/01 $(2008 / 10 / 01))$. Since the ordinate is chosen logarithmic scale, so far it appears that the likelihood of a financial crisis for more than forty orders of magnitude smaller than the background levels of probability. Assuming that the financial crisis was formed by chance, the probability of such an event within the framework of the considered system performance terribly small, of the order of $10^{-50}$. Such a low probability suggests that the operator of the U.S. economy does exist and he is responsible for the manifestation of the global financial crisis.

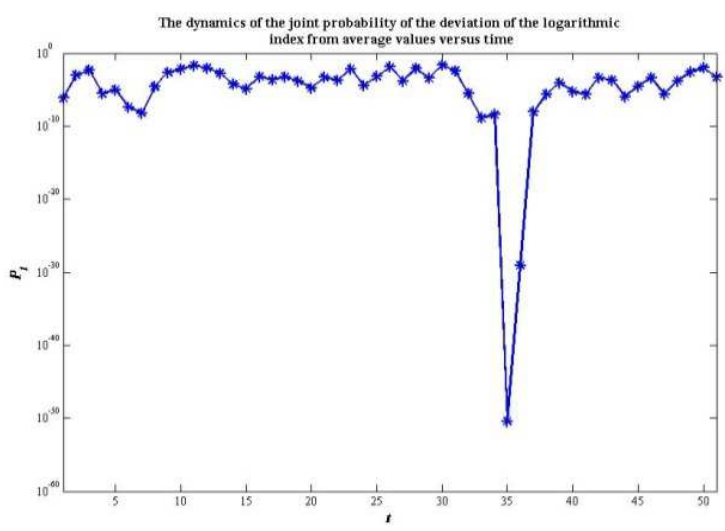

Figure 13. The dynamics of the joint probability of the deviation of the logarithmic index from average values versus time

\section{The Ensemble of Atomic Operators}

Introduced above additive and multiplicative management measures determined at some point in time, as 
far as each of the logarithmic index $L_{t}^{(m)}$ deviated from its mean value. Extreme variations in each of the indices may be associated with variables $\min _{t} L_{t}^{(m)}$ and $\max L_{t}^{(m)}, m=$ $1, \ldots, M$.

We introduce the concept of "atomic operator", $A$, when its logarithmic indexes are defined by the following conditions:

$$
\begin{aligned}
A= & \left(A^{(1)}, \ldots, A^{(M)}\right)= \\
& \left(\left\{\min _{t} L_{t}^{(1)}, \max _{t} L_{t}^{(1)}\right\}, \ldots,\left\{\min _{t} L_{t}^{(M)}, \max _{t} L_{t}^{(M)}\right\}\right) .
\end{aligned}
$$

Easy to understand that the definition (14), there is only $2^{M}$ atomic operators $A_{1}, A_{2}, \ldots, A_{2^{u}}$. For example, in the task of reconstruction of our economic operator United States, where $M=14$, there are only $2^{14}=16384$ atomic operators. If multiplicative management measure is different from zero, this means that the corresponding logarithmic indexes significantly deviate from the respective average values, which indicate one of the predominant influences of the atomic operators.

Table 5. Identification of the atomic operators providing the predominant

\begin{tabular}{|c|c|c|c|c|c|c|c|}
\hline Time & $L_{-} \mathbf{I}$ & $L \_\mathbf{M} 2$ & $L_{-} \mathbf{E D}$ & $L_{-} \mathbf{G D P}$ & $L_{-} \mathbf{U}$ & $L_{-} \mathbf{P I}$ & $L_{-}$IPI \\
\hline$t=6$ & $\min$ & $\max$ & $\max$ & $\min$ & $\max$ & $\min$ & $\min$ \\
\hline$t=35$ & $\min$ & $\max$ & $\min$ & $\min$ & $\max$ & $\min$ & $\min$ \\
\hline Time & $L \_$Retail & $L \_\mathbf{C P I}$ & $L \_\mathbf{I m}$ & $L \_\mathbf{E x}$ & $L \_$ND & $L_{-}$FER & $L \_$FGR \\
\hline$t=6$ & $\min$ & $\min$ & $\min$ & $\min$ & $\min$ & $\min$ & $\min$ \\
\hline$t=35$ & $\min$ & $\min$ & $\min$ & $\min$ & $\max$ & $\min$ & $\min$ \\
\hline
\end{tabular}
influence in the current time

Returning to the set of logarithmic index dynamics $L_{t}^{(m)}, t$ $=1, \ldots, 51 ; m=1, \ldots, 14$, previously discussed above. Analysis of these data in terms of the multiplicative management measures revealed two instants $t=6$, 35, when all 14 logarithmic index on 0,05 significantly deviated from the respective average values. After analyzing the signs of deviation from the mean values can build a Table 5. The Table 5 identified two atomic operators that significantly prevailed over the other at times $t=6,35$. Minima and maxima in the Table 5 are taken from the time series corresponding to a logarithmic index, the name of which is at the intersection of the column and the second row.

We find the additive and multiplicative management measures of atomic statements presented in Table 5, and compare these values with the Table 3 . The data put into a Table 6, which compares the additive and multiplicative management measures manifested in reality atomic operator with atomic operator with minimax logarithmic index Table 5 .
Table 6. Management measures of the atomic operatorsin ideal and reality

\begin{tabular}{ccccc}
\hline Time & \multicolumn{2}{c}{$t=6$} & \multicolumn{2}{c}{$t=35$} \\
\hline $\begin{array}{c}\text { Forms } \\
\text { manifestations }\end{array}$ & Reality & Ideal & Reality & Ideal \\
$\boldsymbol{M}$ c_a & 3,373 & 11,578 & 12,568 & 14,174 \\
$\boldsymbol{M c \_} \boldsymbol{m}$ & 2,857 & 11,132 & 11,299 & 13,834 \\
\hline
\end{tabular}

According to Table 6 atomic operator in the $t=6$ showed in reality an intensity peak less the maximum about three times. Then the operator at $t=35$ appeared in reality almost completely lost in the intensity of only $\approx 18 \%$.

By analogy with atomic operators manifested at 0,05 at $t=$ 6,35 , consider the remaining atomic operators at other values of $t=1, \ldots, 51$. In this case, atomic operator $A_{t}=\left(A_{t}^{(1)}, \ldots, A_{t}^{(14)}\right)$ at time $t$ is determined based on the conditions:

$$
A_{t}^{(n)}=\left\{\begin{array}{l}
\max _{t} L_{t}^{(n)}, L_{t}^{(n)} \geq \operatorname{mean}_{t} L_{t}^{(n)} ; \\
\min _{t} L_{t}^{(n)}, L_{t}^{(n)}<\operatorname{mean}_{t} L_{t}^{(n)} ;
\end{array}\right.
$$

where $n=1, \ldots, 14$.

The question naturally arises: is there the same among the list of 51 atomic operators? To answer this question, we introduce a number $N$ of atomic operator in the binary system, coding zero min and max - the unit. In this case, for example, atomic operators $A_{6}$ and $A_{35}$ as shown in Table 5 number have the following numbers:

$$
N\left(A_{6}\right)=01101000000000 ; N\left(A_{35}\right)=01001000000100 \text {. }
$$

The numbering in the binary system can move the decimal to the well-known formula:

$$
N\left(A_{t}\right)=\sum_{n=1}^{14} N_{n} \cdot 2^{n-1},
$$

where $N_{n}=\{0,1\}, n=1, \ldots, 14-$ the binary representation of numbers. In this case, $N$ goes from 0 to $2^{14}-1=16383$. For example, the decimal number $N\left(A_{6}\right)=22, N\left(A_{35}\right)=2066$.

As part of the special program were found decimal numbers of all operators in the atomic number of 51. They were all different.

Since, in general, the variables are interrelated, and are related the individual atomic operators. For this reason, their pure manifestation in reality in all its power management is apparently rare event. We can only speak of a degree of approximation to the ideal, as was the case for the operator, characterized by the global financial crisis $(t=35)$. This operator is not held in intensity to a maximum of $18 \%$.

Accounting for the relationship between the logarithmic indexes will reduce the number of atomic operators with discernible chances manifestation in reality. From the point of view of the problem of predicting the worst case situation appears when each of the $2^{14}$ atomic operators have the same probability of $2^{-14}$ for the manifestation in the reality. In this case, the prediction uncertainty grows to the maximum number of selection alternatives in the volume $2^{14}$. 


\section{Control Scheme Economic Indicators}

We form the average scheme operator control of the U.S. economy. To do this, first draw a correlation analysis using data on the logarithmic indexes the length of time $2000 / 01 / 01,2000 / 04 / 01, \ldots, 2012 / 07 / 01$. These data have been previously presented as a matrix $L_{t}^{(m)}, t=1, \ldots, 51 ; m$ $=1, \ldots, 14$. Fig. 14 shows the correlation matrix of each logarithmic index to each other. Red color allocates correlation coefficients significant at the 0,05 level. Large a size indicated by the correlation coefficients greater than 0,7 in absolute value.

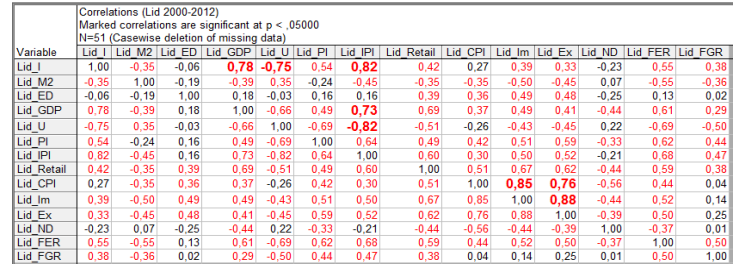

Figure 14. The correlation matrix of each of the logarithmic index with each other

According to the table in Fig.14 of the correlation coefficients, exceeding the value of 0,7 - eight. In the Table 7 eight highly concentrated correlated pairs of indices.

Table 7. Eight highly correlated pairs of indices

\begin{tabular}{llll}
\hline$r\left(L_{-} \mathbf{I}, L_{-} \mathbf{G D P}\right)$ & $r\left(L_{-} \mathbf{I}, L_{-} \mathbf{U}\right)$ & $r\left(L_{-} \mathbf{I}, L_{-} \mathbf{I P I}\right)$ & $r\left(L_{-} \mathbf{G D P}, L_{-} \mathbf{I P I}\right)$ \\
\hline 0,78 & $-0,75$ & 0,82 & 0,73 \\
$r\left(L_{-} \mathbf{U}, L_{-} \mathbf{I} \mathbf{I P I}\right)$ & $r\left(L_{-} \mathbf{C P I}, L_{-} \mathbf{I m}\right)$ & $r\left(L_{-} \mathbf{C P I}, L_{-} \mathbf{E x}\right)$ & $r\left(L_{-} \mathbf{I m}, L_{-} \mathbf{E x}\right)$ \\
$-0,82$ & 0,85 & 0,76 & 0,88 \\
\hline
\end{tabular}

According to Table 7, the maximum value 0.88 of correlation occurs between the import index, $L \_I m$ and exports index, $L_{-}$Ex. This can be interpreted as the fact that the regulation of imports and exports is carried out on one scenario.

Fig.15,a pair of graphs shows the indices of imports and exports. Visually, it is clear that they were related. The slightly lower value of 0,85 has a correlation between indices of consumer prices, CPI and import, Im, i.e. this pair of indices from the point of view of the operator is controlled the same way.

The correlation coefficients between the index of industrial production, $L$ IPI and the dynamics of private gross investment, $L_{-}$I, and the ratio of the number of unemployed to the economically active population, $L_{-} \mathrm{U}$ were 0,82 and $-0,82$ respectively. The negative value of the correlation coefficient between $L_{-}$IPI and $L_{-} U$ can be interpreted in a natural way, i.e., with an increase in the index of industrial production is growing demand for personnel and, as a consequence, unemployment is falling. Fig.15,b shows the joint logarithmic graphs of indices of industrial production and unemployment in the United States.

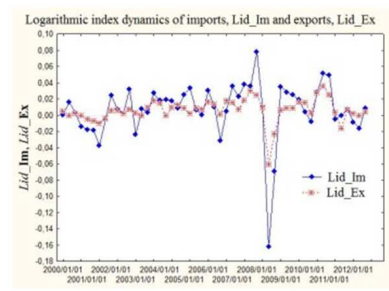

(a)

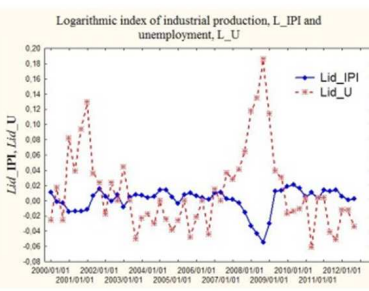

(b)
Figure 15. A pair of graphs of logarithmic indexes of imports, Lid_Im and exports, Lid_Ex, (a); a pair of logarithmic indexes plots of industrial production indices, Lid_IPI and unemployment, Lid_U, (b)

Diagrams depict the correlations, including those that are in absolute value exceeds a certain threshold value $K_{c}$. Fig.16 shows the circuit that present economic indicators related correlation of the connections. The absolute values of the correlations between the logarithmic index exceeds 0,8 ; 0,7; and 0,6 for Fig.16,a, Fig.16,b, Fig.16,c respectively. The solid lines represent positive and dashed - negative values of correlation coefficients.

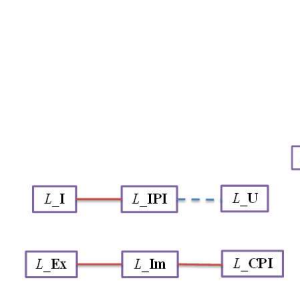

(a)

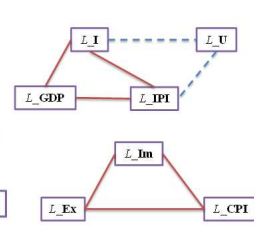

(b)

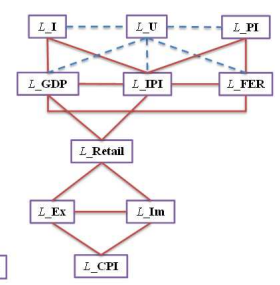

(c)
Figure 16. The system of correlations in excess of the absolute value of the value of $0,8,(a) ; 0,7,(b) ; 0,6,(c)$

From Fig.16, a it follows that when the absolute value of correlation coefficients are larger than 0,8 , are available two independent unit of economic management. The first unit can be summarized in the form of a bundle of "investment — production — unemployment", the second unit - under the "export - import - consumer prices". These two are the basic economic unit for the U.S. economy. These two units, with some additions remain (Fig.16,b) and taking into account the correlation coefficients are larger than 0,7 .

Thus, from the viewpoint of high correlated logarithmic index values U.S. economy is divided into two units. The first might be called "Unit of the real economy", because it includes management indicators such as investment, I, production, IPI, unemployment, U, and the gross domestic product, GDP. The second could be called "Consumer unit containing an import-export industry", because it involves such a sensitive area, as consumer prices, CPI and import-export operations, Ex, Im.

According to the diagrams Fig.16,a,b, the operator of the U.S. economy prefers to accelerate the economy, lowering unemployment. It also increases consumer prices, along with increased exports and imports.

Finally, if the registration threshold of correlation coefficients $K_{c}$ lowered to 0,6 , the blocks of the real 
economy and consumption to export-import operations are combined (Fig.16,c), and this association is through the retail trade, Retail.

According to the correlation matrix shown in Fig.14, highly significant at the 0,05 level are 71 coefficients. All these correlation coefficients are in absolute value greater than the value of 0,29 . A total of pair correlation coefficients $(14 \times 13) / 2=91$.

Logarithmic index dynamics can be represented as matrix $L=L_{t}^{(m)}, t=1, \ldots, 51 ; m=1, \ldots, 14$ of $51 \times 14$, while the columns of the logarithmic index $L$ are the time series of the individual indexes. We define the matrix of sample correlation coefficients $K$ logarithmic index dynamics according to the following formula:

$$
K_{n, m}=\operatorname{corr}\left(L^{(n)}, L^{(m)}\right), n, m=1, \ldots, 14,
$$

where $\operatorname{corr}(X, Y)$ - normal sample correlation coefficient determined by the formula:

$$
\begin{aligned}
\operatorname{corr}(X, Y) & =\frac{\sum_{t}\left(X_{t}-\bar{X}\right)\left(Y_{t}-\bar{Y}\right)}{\sqrt{\sum_{t}\left(X_{t}-\bar{X}\right)^{2} \cdot \sum_{t}\left(Y_{t}-\bar{Y}\right)^{2}}}, \\
\bar{X} & =\operatorname{mean}(X), \bar{Y}=\operatorname{mean}(Y) .
\end{aligned}
$$

Note that in Fig.14 shows exactly the matrix (15), the pair correlation coefficients of which are calculated according to the formula $\left(15^{\prime}\right)$.

Available at some point in time $t, t=1, \ldots, 51$ set of indexes $\left\{L_{t}^{(1)}, \ldots, L_{t}^{(14)}\right\}$ can always be identified with one of the atomic operators $A_{t}$ according to the rule:

$$
\begin{aligned}
A_{t}=\left(A_{t}^{(1)}, \ldots, A_{t}^{(14)}\right), \\
A_{t}^{(m)}=\left\{\begin{array}{l}
\max L^{(m)}, L_{t}^{(m)} \geq \operatorname{mean}\left(L^{(m)}\right) ; \\
\min L^{(m)}, L_{t}^{(m)}<\operatorname{mean}\left(L^{(m)}\right) .
\end{array}\right.
\end{aligned}
$$

We state in mathematical language of atomic operator updating procedure (16), i.e. the transition from a set of extreme indices $\left\{A_{t}^{(1)}, \ldots, A_{t}^{(14)}\right\}$ to the real $\left\{L_{t}^{(1)}, \ldots, L_{t}^{(14)}\right\}, t=$ $1, \ldots, 51$. The transition will be determined by the prevailing system of correlations (15).

We introduce an unknown set of indexes $\left\{F_{q}^{(1)}, \ldots, F_{q}^{(14)}\right\}$ and define a set of time series of the form:

$$
P^{(m)}=\left\{L_{1}^{(m)}, \ldots, F_{q}^{(m)}, \ldots, L_{51}^{(m)}\right\},
$$

where $m=1, \ldots, 14$. In (17) on the $q$-th put a set of indices $F_{q}^{(m)}, m=1, \ldots, 14$.

Taking into account (17), we define the correlation matrix

$$
S_{n, m}=\operatorname{corr}\left(P^{(n)}, P^{(m)}\right), n>m,
$$

which sets the schema relationship between logarithmic index operators.

Unknown index set $\left\{F_{q}^{(1)}, \ldots, F_{q}^{(14)}\right\}$ will be chosen so as to ensure the proximity of the two systems correlations (15) and (18) at a predetermined value of the parameter $K_{c}$. In mathematical form of affinity matrix pair (15) and (18) can be represented, for example, as a problem of minimizing the following:

$$
D=\sum_{\substack{n>m ; \\\left|K_{n, m}\right|>K_{c}}}\left(S_{n, m}-K_{n, m}\right)^{2} \rightarrow \min
$$

According to (19), the closer the sum of $D$ to zero, the closer the correlation matrix (15) to the correlation matrix (18) in the part of the matrix elements that satisfy $\left|K_{n, m}\right|>K_{c}$. Approximation to the minimum amount (19) will work with varying magnitudes $F_{q}^{(m)}, m=1, \ldots, 14$.

It is known that a necessary condition for the minimum function of several variables is the condition of zero corresponding partial derivatives, i.e.

$$
\frac{\partial D}{\partial F_{\varphi}^{(n)}}=0
$$

where $n=1, \ldots, 14$.

We substitute (19) into (20), then, after differentiation, we find the following equation to find the unknown $F_{q}^{(n)}, n=$ $1, \ldots, 14$ :

$$
\begin{aligned}
& \left(F_{q}^{(n)}-\overline{P^{(n)}}\right) \sum_{\substack{m \neq n,\left|K_{n, m}\right|>K_{c}}} S_{n, m}\left(S_{n, m}-K_{n, m}\right)- \\
& \quad \sqrt{\sum_{t}\left(P_{t}^{(n)}-\overline{P^{(n)}}\right)^{2}} \sum_{\substack{m \neq n, n \\
\left|K_{n, m}\right| K_{c}}} \frac{\left(S_{n, m}-K_{n, m}\right)\left(F_{q}^{(m)}-\overline{P^{(m)}}\right)}{\sqrt{\sum_{t}\left(P_{t}^{(m)}-\overline{P^{(m)}}\right)^{2}}}=0,
\end{aligned}
$$

where $n=1, \ldots, 14$.

Look for the minimum of (19) will be using MATLAB solver. To take advantage of this solver, you need to know

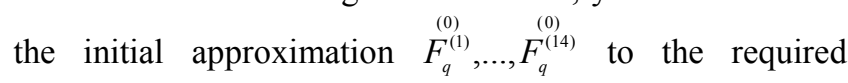
minimum. Let us choose as an initial approximation atomic operator (16), i.e.

$$
F_{q}^{(0)}=A_{q}^{(n)},
$$

where $n=1, \ldots, 14$. The minimization problem (19), (22) was solved for each $q=1, \ldots, 51$. The search was carried out after a minimum starting from a position corresponding to an atomic operator.

To better address the problem of minimizing (19), (22) we used MATLAB solver, which allows you to find the root of the system of algebraic equations (21) and, thus, to specify the initial values in the iterative process of finding the minimum of (19). The sequence of calculations was the following set of steps: 1) solved the problem of minimizing (19), (22), and 2) received preliminary values of the minimum considered as initial values when searching for the root of an algebraic system of equations (21), and 3) re-solved the problem of minimizing (19), (22), whereas initial values chosen root of an algebraic system of equations. This three-tier procedure afforded a minimum of (19) in all cases, i.e. when $q=1, \ldots, 51$.

After the counting of the additive and multiplicative management measures $M c \_a_{q}, M c \_m_{q}, q=1, \ldots, 51$ at $\alpha=0,05$ 
and $K_{c}=0,29$, it turned out that they do not differ from those of controls found on the original data and shown in Fig.11.

Note that in the scheme of correlation with $K_{c}=0,29$ of 71 highly significant relationships. It is possible to obtain at the start from the initial data (22) is approximately the same distribution of the additive and multiplicative management measures, as well as for measures constructed from the raw data and presented earlier in Fig.11. Thus, consideration of all pairs of highly significant correlations provided the reproduction management measures specific to the source data.

\section{The Procedure for Forecasting of the U.S. Economy}

We do not predict the economic indicators but the corresponding logarithmic dynamics index. According to the previous paragraph logarithmic dynamics index significantly correlated.

We now define the period, $\tau$, which will be the prognosis. For example, if the weather is one quarter ahead, i.e. on $2013 / 01 / 01$, the $\tau=1$. If the forecast is for the whole of 2013, then $\tau=4$.

We define the parameter $T$, which describes the number of times that counted in the correlation matrix (18). In general, the parameter $T$ can be set to $1,2, \ldots, 51$. Introduction of the assumptions in the calculation of the correlation matrix (18) to receive the predicted values, control measures which are comparable with those obtained by the source data. If we assume that $T=51$, within the limits of the proposed procedure forecasting cannot achieve the necessary additive control measures.

Originally restrict the forecast for one quarter in advance, i.e. $\tau=1$. Let U.S. economic operator characterized by a set of time series of the form:

$$
P^{(n)}=\left\{L_{52-T}^{(n)}, \ldots, L_{51}^{(n)}, F_{52}^{(n)}\right\},
$$

where $n=1, \ldots, 14$. Unknown quantities in the time series (23) are variable $F_{52}^{(n)}, n=1, \ldots, 14$. In total, therefore, necessary to estimate the unknown 14 logarithmic index operator.

Taking into account (23), we define the correlation matrix $S_{n, m}$, similar to the matrix (18). When forecasting the unknown values of the indices in the moment of time $t=52$ we start from the requirement that the correlation matrix $S_{n, m}$ was close to the well-known matrix (15). As varying variables that provide proximity of the two matrices (15), (18), will be performing projected indexes operator $F_{52}^{(n)}, n=1, \ldots, 14$.

To ensure the proximity of the two matrices (15) and (18) we write the minimization condition similar to (19) - (21). Type of function to be minimized (19) remains unchanged at the forecast step forward. Conditions (20) can be rewritten as

$$
\frac{\partial D}{\partial F_{32}^{(n)}}=0
$$

where $n=1, \ldots, 14$.

We substitute (19) into (24), then, after differentiation, we find the following equation to find the unknown $F_{52}^{(n)}, n=$ $1, \ldots, 14$ :

$$
\begin{aligned}
& \left(F_{52}^{(n)}-\overline{P^{(n)}}\right) \sum_{\substack{m \neq n,\left|K_{n, m}\right|>K_{c}}} S_{n, m}\left(S_{n, m}-K_{n, m}\right)- \\
& \sqrt{\sum_{t}\left(P_{t}^{(n)}-\overline{P^{(n)}}\right)^{2}} \sum_{\substack{m \neq n,\left|K_{n, m}\right|>K_{c}}} \frac{\left(S_{n, m}-K_{n, m}\right)\left(F_{52}^{(m)}\right) \overline{\left.P^{(m)}\right)}}{\sqrt{\sum_{t}^{\left(P_{t}^{(n)}-P^{(m)}\right)^{2}}}}=0,
\end{aligned}
$$

where $n=1, \ldots, 14$.

When minimization of the quantity (19) by varying values $F_{52}^{(n)}, n=1, \ldots, 14$ is necessary to know the initial approximation to a minimum $F_{52}^{(1)}, \ldots, F_{52}^{(14)}$. As an initial approximation of the procedure we consider the random selection of one of a set of atomic operators $2^{14}$ according to the algorithm:

$$
F_{52}^{(0)}=\left\{\min _{52-T \leq t \leq 51}\left(L_{t}^{(n)}\right), \max _{52-T \leq t \leq 51}\left(L_{t}^{(n)}\right)\right\},
$$

where $n=1, \ldots, 14$. In (26) in the figure brackets is assumed the equally probable choice of either a minimum or maximum for each log-index $n=1, \ldots, 14$.

The problem (19), (23) - (26) was solved $K=10^{3}$. The most suitable value was the value of $T=48$. Fig. 17 shows the results of solving the problem (19), (23) - (26) $K=10^{3}$. According to Fig. 17 the mean score of the additive control measures was equal to 2,34, which was considered quite satisfactory approximation to the value of 2,32, which was found in the existing set of indexes. Thus, the forecast one step ahead succeeded with the help of selection parameter $T$ to construct a scheme of correlations that it allowed the forecast average level of the additive control measures. It should be noted simulation results shown in Fig.17, the additive measure of control takes four typical values and multiplicative measure of control is indistinguishable from zero.

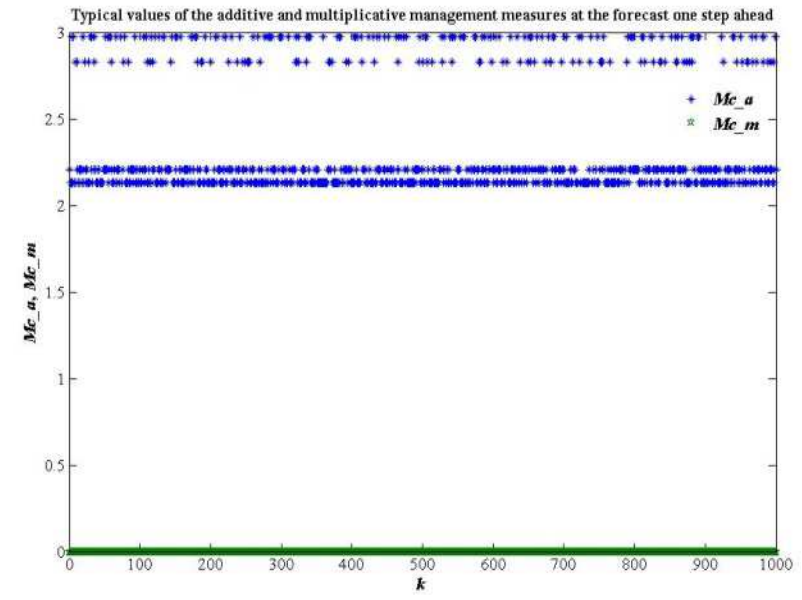

Figure 17. Additive and multiplicative management measures projected values for one step at $T=48$ 
We make a prediction of the fourteen indicators into four steps forward, i.e. for 2013, while $\tau=4$. We rewrite (23) as follows:

$$
P^{(n)}=\left\{L_{52-T}^{(n)}, \ldots, L_{51}^{(n)}, F_{52}^{(n)}, \ldots, F_{55}^{(n)}\right\},
$$

where $n=1, \ldots, 14$, and $T$ according to the previous calculation is 48 , i.e. $T=48$.

Taking into account (27), we find the matrix $S_{n, m}$ and solve the problem of minimizing the magnitude (19). As unknowns in the minimization problem we consider 56 projected values $F_{52}^{(1)}, \ldots, F_{52}^{(14)}, \ldots, F_{55}^{(14)}$. Algebraic equations of the type similar to (25) are easily obtained from (25) after the changes: $F_{52}^{(n)} \rightarrow F_{53}^{(n)}, F_{52}^{(n)} \rightarrow F_{54}^{(n)}, F_{52}^{(n)} \rightarrow F_{55}^{(n)}$. Find the minimum of (19) is in the same way that the forecast of one step forward. We define an initial approximation $F_{52}^{(1)}, \ldots, F_{52}^{(14)}, \ldots, F_{55}^{(0)}$ to the required minimum.

The initial approach $F_{52}^{(1)}, \ldots, F_{52}^{(14)}, \ldots, F_{55}^{(14)}$ will form in two stages. First, using ARIMA models we construct forecast for 2013, denote this as a prediction $\left\{Z_{52}^{(n)}, \ldots, Z_{55}^{(n)}\right\}$. Second, we associate with each logarithmic index included in the correlations corresponding to the atomic operator. Combining the first and second phases, we have

$$
F_{t}^{(0)}=\left\{\begin{array}{l}
\max _{52-T \leq t \leq 51}\left(L_{t}^{(n)}\right), Z_{t}^{(n)} \geq \operatorname{mean}_{52-T \leq t \leq 51}\left(L_{t}^{(n)}\right) ; \\
\min _{52-T \leq t \leq 51}\left(L_{t}^{(n)}\right), Z_{t}^{(n)}<\operatorname{mean}_{52-T \leq t \leq 51}\left(L_{t}^{(n)}\right) ;
\end{array}\right.
$$

where $n=1, \ldots, 14$.

To construct $\left\{Z_{52}^{(n)}, \ldots, Z_{55}^{(n)}\right\}$ could be used technology build linear regression models. However, it was not very comfortable, as 13 out of 14 of the regression coefficients are not significant at the 0,05 level. The only significant regression coefficient is an index of U.S. government debt $\left(L \_N D\right)$. In this connection to construct $\left\{Z_{52}^{(n)}, \ldots, Z_{55}^{(n)}\right\}$ the ARIMA $(p, d, q)$ model were examined for each logarithmic index.

\begin{tabular}{|c|c|c|c|}
\hline$L \_x^{(m)}$ & $L_{-} \mathbf{I}$ & $L_{-} \mathbf{M 2} L_{-} \mathbf{E D} L_{-} \mathbf{G D P} L_{-} \mathbf{U} \quad L_{-} \mathbf{P I}$ & $L_{-} \mathbf{I P I}$ \\
\hline $\operatorname{ARIMA}(p, d, q)$ & $(1,1,1)$ & $(3,1,0)(0,1,2)(1,1,1) \quad(1,1,0)(1,1,1)$ & $(1,1,2)$ \\
\hline$L \_x^{(m)}$ & $L_{-}$Retai & $L_{-} \mathbf{C P I} L_{-} \mathbf{I m} L_{-} \mathbf{E x}$ & $L_{-} \mathbf{F G R}$ \\
\hline $\operatorname{ARIMA}(p, d, q)$ & $(1,1,1)$ & $(0,1,3)(2,1,1)(1,0,0) \quad(2,1,0)(1,1,1)$ & $(2,1,0)$ \\
\hline
\end{tabular}

Table 8. Model ARIMA(p,d,q) for the prediction for 2013 of 14 indexes
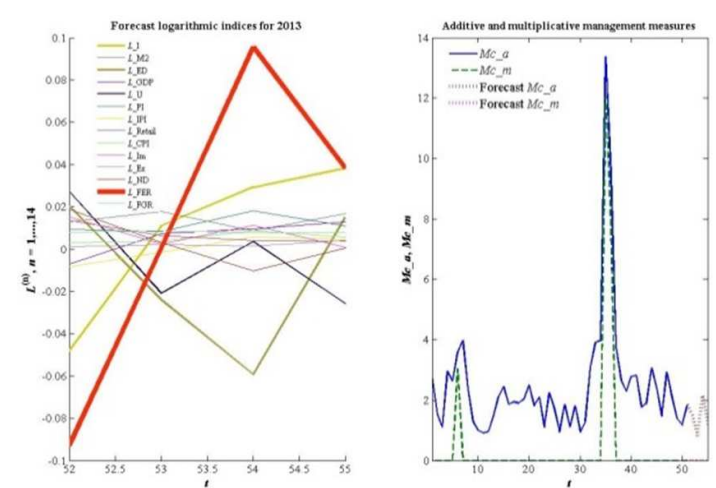

Figure 18. Forecast logarithmic indices for 2013 (left panel) and the additive and multiplicative operator control measures for the entire length of timeplus the forecast for 2013 (right panel)

Table 8 shows the corresponding models $\operatorname{ARIMA}(p, d, q)$ for each of the 14 logarithmic indices. All coefficients of models shown in Table 8 significant at 0,05 . These models are built on the assumption that the orders of the autoregression $(p)$, moving average $(q)$ and the number of differences $(d)$ were the highest, provided significance at 0,05 level of coefficients and that $d \leq 1$.

Fig. 18 shows the results of the numerical solution of the problem of minimizing the quantity (19) subject to (27), (28). The left in Fig. 18 shows the 14 schedules, forecast indices at 2013. Line thickness characterizes the degree of variability in the index. On the right in Fig. 18 shows graphs of the additive and multiplicative management measures for the available time points plus the forecast for 2013 .

\section{Analysis of the U.S. Economic Forecast for 2013}

According to the left graph in Fig.18 in the top three on the variability included, in descending order: $L_{-}$FER, $L_{-}$I, $L$ ED.

The most variable during the 2013 will make index the federal funds rate. Index rates will rise in the first three quarters of 2013, the growth of the index will change fall in the fourth quarter.

The index of the dynamics of gross private investment, L_I will grow throughout 2013.
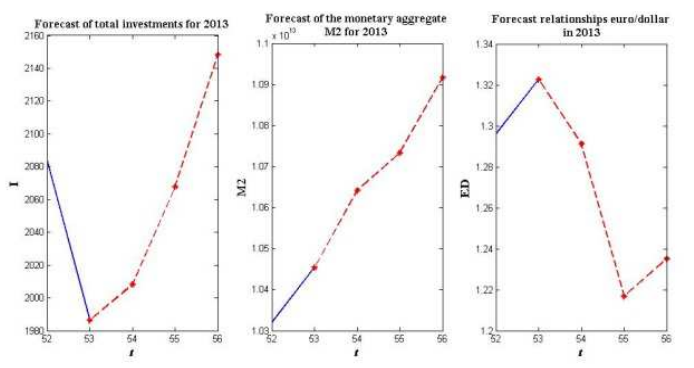

Figure 19. Forecast for 2013 of the dynamics of gross investment, I; monetaryaggregate, M2; relationship euro/dollar, ED

The index for the euro/dollar, $L$ ED, will shrink in the first half of 2013 and the rise in the second half of 2013. 
Given the outlook index for 2013, will study the behavior of the forecast indicators. Fig. $19-23$ shows the required forecast for 2013 all 14 indicators.
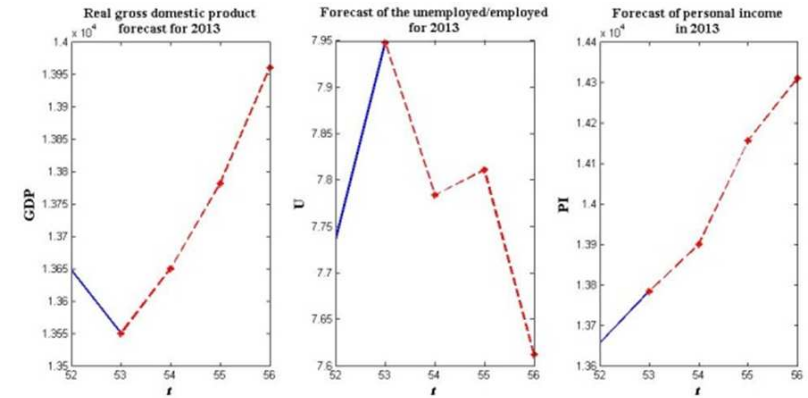

Figure 20. Forecast for 2013 real gross domestic product, GDP; relations unemployed/employed, $U$; dynamics of personal income, $P I$

According to Fig.19 for 2013 gross private investment and the monetary aggregate M2 will grow. The ratio of the euro/dollar will fall in the first three quarters of 2013, and a few will grow in the fourth quarter.

According to Fig.20 for the 2013 real gross domestic product and personal income will grow. The ratio of unemployed/employed during 2013 as a whole will fall.

According to Fig. 21 for 2013 retail sales and consumer price index will rise. The index of industrial production, starting from the second quarter of 2013 is expected to grow.
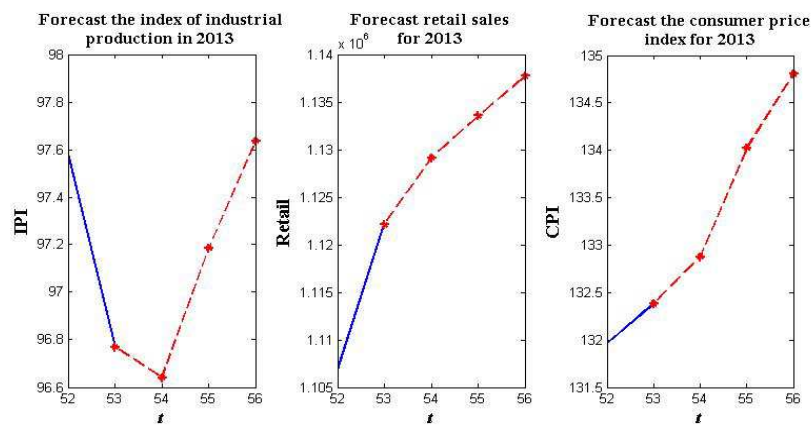

Figure 21. Forecast for 2013 the index of industrial production, IPI; retail trade, Retail; consumer price index, CPI

According to the Fig.22 in 2013 imports and exports will increase. U.S. government debt in the second and third quarters of falls, but in the fourth quarter to rise again.
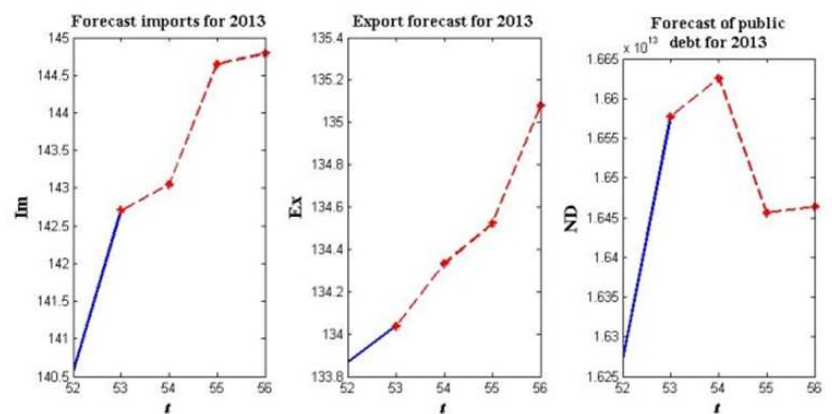

Figure 22. Forecast for 2013 imports, Im; exports, Ex; public U.S. debt, $N D$
According to the Fig.23 in the 2013 effective tax rate on federal funds and revenues will grow.
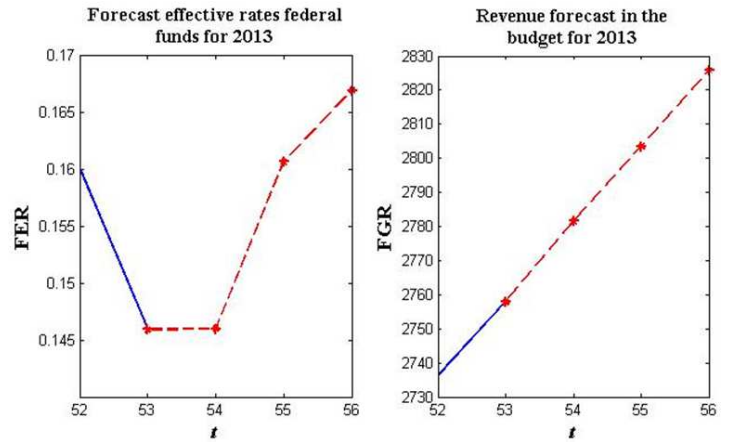

Figure 23. Forecast for 2013 the effective federal funds rate, FER;revenue dollars, FGR

If you go back to the right graph in Fig.18, where the built additive and multiplicative management measures plus a forecast for 2013, the overall conclusion is obvious. There is nothing extraordinary in the behavior of the U.S. economy for 2013 is not expected.

\section{Conclusion}

In this article, we study the U.S. economy in terms of its management. In other words, the reconstruction so-called operator of the U.S. economy. To identify the economic operator entered logarithmic dynamics index for each economic indicator. A total of 14 economic indicators into account.

Determined the additive and multiplicative measures of economic management to the operator. During the period from $2000 / 01 / 01$ to $2012 / 07 / 01$ at a frequency of one quarter were found two points in time (2001/07/01, 2008/10/01), when the operator fully manifested itself. This is reflected in the fact that the logarithmic index of 14 economic indicators simultaneously significantly (at 0,05) deviate from the respective average values.

The scheme operator controls the U.S. economy on the basis of accounting statistically significant correlations, which, as it turns out, there are 71 out of the entire set of binary correlations - 91. The revealed correlations scheme is to some extent a virtual, because tied to the observation of the segment of the economy by the U.S. from 2000/01/01 to $2012 / 07 / 01$. It was revealed scheme of correlation in the management of the U.S. economy acts as a foundation of the reconstructed economic operator. U.S. economic operator itself can be represented as an ensemble of the so-called atomic operators by which is generally equal to $2^{14}$. Atomic operators can manifest itself in reality in varying degrees. For example, at the start of the global financial crisis (2008/10/01) the corresponding atomic operator could have collected up to $18 \%$ of its maximum intensity.

A scheme of the forecast for 2013 administrative actions of the operator based on the forecast of logarithmic dynamics index. The forecast is based on the extrapolation 
scheme of correlation between the logarithmic dynamics index. Prediction logarithmic index, in turn, led to forecast 2013 all 14 economic indicators.

During 2013 gross private investment and monetary aggregate M2 to grow, the ratio of the euro/dollar will fall in the first three quarters of 2013, and a few will grow in the fourth quarter, real gross domestic product and personal income will grow, the ratio of unemployed/employed for 2013 as a whole will fall, retail sales and consumer price index will rise, the index of industrial production, starting from the second quarter of 2013 will increase, and imports and exports will grow, the U.S. national debt in the second and third quarters will fall, but in the fourth quarter to rise again, the effective rate on federal funds and revenues will grow.

Overall, in 2013 the U.S. economy is predicted quite favorable and identify any crisis within the framework of this approach fails.

\section{Acknowledgements}

The author is grateful for help in translating article V.N. Nikolenko.

\section{References}

[1] Nassim Taleb, The black swan: the impact of the highly improbable, London: Penguin, 2008.

[2] K.E. Plokhotnikov, Fundamentals of econometrics in the package STATISTICA: Textbook, Moscow: University textbook, 2010, 298p., CD.
[3] K.E. Plokhotnikov, The Russian Economy in the Global Context/ Futurological Congress: the future of Russia and the world: Materials of the Scientific Conference, 4 June 2010, Moscow, 2010, pp.482 - 512 .

[4] Data were collected during January — February 2013.

[5] http://research.stlouisfed.org/fred2/series/GPDI/downloadda ta? $\mathrm{cid}=112$

[6] http://research.stlouisfed.org/fred2/series/MYAGM2USM05 $2 \mathrm{~N} /$ downloaddata? $\mathrm{cid}=32267$

[7] http://www.imf.org/external/index.htm

[8] http://www.research.stlouisfed.org/fred2/graph/?s[1][id] $=\mathrm{G}$ DPC1

[9] http://www.miseryindex.us/

[10] http://www.bea.gov

[11] http://research.stlouisfed.org/fred2/series/INDPRO/downloa ddata?cid $=3$

[12] http://www.economagic.com/em-cgi/data.exe/cenret/nrt100s a

[13] http://data.bls.gov/pdq/SurveyOutputServlet

[14] http://www.treasurydirect.gov/NP/BPDLogin?application=n $\mathrm{p}$

[15] http://www.federalreserve.gov/releases/h15/data.htm\#top

[16] http://www.bea.gov

[17] These evaluations were carried out in the MATLAB package 